\title{
STUDY OF A 10-MW CONTINUOUS SPALLATION NEUTRON SOURCE
}

\author{
H. Ludewig, A.G. Ruggiero and S. Shapiro
}

November 14, 2003

\author{
Physics Department \\ Brookhaven National Laboratory \\ Operated by \\ Brookhaven Science Associates \\ Upton, NY 11973
}

Under Contract with the United States Department of Energy

Contract Number DE-AC02-98CH10886 


\section{DISCLAIMER}

This report was prepared as an account of work sponsored by an agency of the United States Government. Neither the United States Government nor any agency thereof, nor any of their employees, nor any of their contractors, subcontractors or their employees, makes any warranty, express or implied, or assumes any legal liability or responsibility for the accuracy, completeness, or any third party's use or the results of such use of any information, apparatus, product, or process disclosed, or represents that its use would not infringe privately owned rights. Reference herein to any specific commercial product, process, or service by trade name, trademark, manufacturer, or otherwise, does not necessary constitute or imply its endorsement, recommendation, or favoring by the United States Government or any agency thereof or its contractors or subcontractors. The views and opinions of authors expresses herein do not necessarily state to reflect those of the United States Government or any agency thereof. 


\title{
STUDY OF A 10-MW CONTINUOUS SPALLATION NEUTRON SOURCE*
}

\author{
A.G. Ruggiero, H. Ludewig, S. Shapiro, BNL, Upton, NY 11973, USA
}

\section{Abstract}

This paper reports on the feasibility study of a proton Super-Conducting Linac as the driver for an Acceleratorbased Continuous Neutron Source (ACNS) [1] to be located at Brookhaven National Laboratory (BNL). The Linac is to be operated in the Continuous Wave (CW) mode to produce an average $10 \mathrm{MW}$ of beam power. The Linac beam energy is taken to be $1.25 \mathrm{GeV}$. The required average proton beam intensity in exit is then $8 \mathrm{~mA}$.

\section{INTRODUCTION}

It is commonly agreed that a Super-Conducting Linac (SCL) is the most effective choice for a continuous highpower proton beam in the $\mathrm{GeV}$ range. Other devices, like Cyclotrons or Fixed-Field Alternating-Gradient accelerators, should also be considered, but they are less efficient and are more prone to uncontrolled beam losses.

A SCL is also most suitable for a continuous mode of operation $(\mathrm{CW})$, where average and peak performance are equal, as opposed to a pulsed mode where the peak performance determines the design and requirements. The design of SCL is simplified with the CW mode of operation, since it avoids large excursion between average and peak values, and related fatigue effects. In the $\mathrm{CW}$ mode the concern with cavity Filling Time and Lorentz Forces are removed.

Though the feasibility of SCL is within present mechanical, cryogenic, and RF technology, it has nonetheless not been proven entirely yet. One SCL is presently being build for the Spallation Neutron Source (SNS) [2] project; and another has been proposed and conceptually designed for the AGS Upgrade at Brookhaven [3]. The Accelerator-based Continuous Neutron Source (ACNS) can also make use of a similar SCL. Despite the larger average beam power required, it compares favorably with the other two projects, as it can be seen from the comparison in Table 1.

The proposed SCL driver for the ACNS accelerates protons to $1.25 \mathrm{GeV}$, operates in the $\mathrm{CW}$ mode, and generates an average beam power of $10 \mathrm{MWatt}$. The average beam current is $8 \mathrm{~mA}$, and the total length of the superconducting section about $160 \mathrm{~m}$. The Linac is made of three parts: a Front-End, that is a $10 \mathrm{~mA}$ ion source followed by a $2-\mathrm{MeV}$ RFQ, a room temperature $200-\mathrm{MeV}$ Drift-Tube Linac (DTL), and the Super-Conducting Linac (SCL) proper. This in turn is made of three sections: the low-energy (LE) section that accelerates protons to 400 $\mathrm{MeV}$, the medium-energy (ME) section for further acceleration to $800 \mathrm{MeV}$, and the high-energy (HE) section that accelerates to the final energy of $1.25 \mathrm{GeV}$.

* Work performed under the Contract Number DE-AC02$98 \mathrm{CH} 10886$ with the auspices of the U.S. Department of Energy.
The selected operating frequency of the room temperature components, RFQ and DTL, is $350 \mathrm{MHz}$; the LE section of the SCL captures and accelerates the beam at $700 \mathrm{MHz}$, whereas the last two sections can either operate also at $700 \mathrm{MHz}$ or at $1,400 \mathrm{MHz}$. In the first case we rely on available industrial RF power sources, in the latter case the RF power sources, at twice the frequency, need to be demonstrated and developed, but could allow a shorter length of the accelerator and be more economical. In any case, the study has shown that the accelerator is feasible, can be built in a relatively short period of few years, and has an estimated total cost for the superconducting sections of about $100 \mathrm{M}$.

\section{REQUIREMENTS OF THE PROTON DRIVER}

The accelerator driver of the ACSN facility is schematically shown in Figure 1 . The proton beam aims directly to the core, and can be placed either underneath or above the target, with Figure 1 showing the former case. The actual location of the accelerator with respect to the target and the interface with final transport, bend and the target itself remain to be investigated.

Acceleration of positive-ions (protons) is assumed, since there is no requirement for the injection in a subsequent circular storage device as in the SNS project. For the same reason, the beam in exit of the RFQ does not need to be pre-chopped.

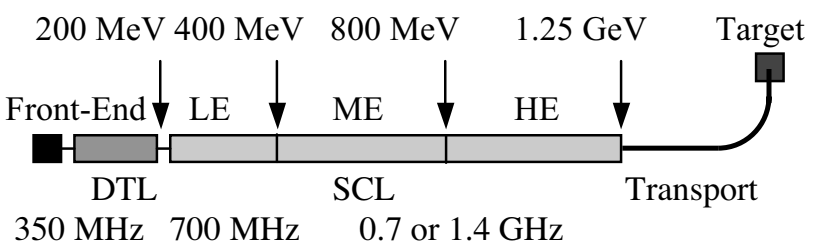

Figure 1. Layout of the 1.25-GeV, 10-MW SCL

The Front-End is made of an Ion Source placed on a platform at $35-50 \mathrm{kVolt}$. It has a continuous beam output of $10 \mathrm{~mA}$. It is followed by a $350-\mathrm{MHZ}$ RFQ which focus, bunch and accelerate the beam to about $2 \mathrm{MeV}$. At the exit, the beam bunches are compressed sufficiently to be squeezed within the rf buckets of the Drift-Tube Linac (DTL) which operates also at $350 \mathrm{MHz}$. Because of the relatively low beam current, and the absence of stringent requirements on the beam emittance and momentum spread, space-charge effects are not expected to play a relevant role. As a consequence, no major beam losses are expected in the RFQ. A transmission of $80 \%$ is conservatively assumed, and the beam intensity at the exit 
of the RFQ is $8 \mathrm{~mA}$. We assume that there are no further losses during the transfer of the beam through the rest of the accelerator, all the way down to the Target. At the exit of the SCL, and on the Target, the beam intensity is then 8 $\mathrm{mA}$.

Table 1. Comparison of three SCL Projects

\begin{tabular}{|c|c|c|c|}
\hline & SNS & AGS & ACNS \\
\hline Kinetic Energy, GeV & 1.0 & 1.2 & 1.25 \\
\hline Ave. Power, MW & 1.0 & 0.045 & 10 \\
\hline Duty Factor, $\%$ & 6.0 & 0.18 & 100 \\
\hline Repetition Rate, $\mathrm{Hz}$ & 60 & 2.5 & -- \\
\hline Pulse Length, ms & 1.0 & 0.72 & -- \\
\hline Peak Power, MW & 16.7 & 25 & 10 \\
\hline Ion Source Current, mA & 35 & 35 & 10 \\
\hline Ave. Beam Current, mA & 1.0 & 0.035 & 8 \\
\hline Peak Beam Current, mA & 26 & 21 & 8 \\
\hline Protons / Bunch, x $10^{8}$ & 4.3 & 8.7 & 1.43 \\
\hline $\mathrm{RF}, \mathrm{GHz}$ & 0.805 & $0.805-1,61$ & $0.7-1,4$ \\
\hline Coupler RF Power, MW & $170-350$ & $260-400$ & $80-155$ \\
\hline Length, $\mathrm{m}$ & 158 & 120 & 163 \\
\hline Inj. Energy, MeV & 185.6 & 200 & 200 \\
\hline Cryo. Power $\left(2.1^{\circ} \mathrm{K}\right), \mathrm{kW}$ & 0.5 & 0.15 & 5.3 \\
\hline Ave. AC Power, MW & 3.1 & 0.28 & 23 \\
\hline Ave. Gradient, MV/m & $3.1-6.5$ & $5.3-10.0$ & $3.3-8.7$ \\
\hline Efficiency, \% & $26-30$ & $9-16$ & $35-40$ \\
\hline Capital Cost, $\mathrm{M} \$$ & 110 & 97 & 85 \\
\hline Operation Cost, M\$ / yr & 2.0 & 0.18 & 15.2 \\
\hline
\end{tabular}

Blue - Positive Features

Red - Negative Features

\section{LINAC DESIGN}

In a proton linac there is a large variation of beam velocity, in our case from $\beta=0.08$ at $2 \mathrm{MeV}$ to $\beta=0.90$ at $1.25 \mathrm{GeV}$. The first accelerating section cannot be made of half-wavelength super-conducting RF cavities, though quarter-wavelength super-conducting linear accelerators do exist and are successfully operational. We prefer to assume here a room-temperature conventional Drift-Tube Linac (DTL) operating in a continuous mode. We shall also assume an energy of $200 \mathrm{MeV}$ for this section to ease the design and manufacturing of the RF cavities in the early part of the SCL proper. Also, the RFQ, if desired, can be made super-conducting to ease the concern with the thermal load. Other solutions are of course possible, and they should be examined with a more careful and detailed design.

Thus, the SCL proper starts at $200 \mathrm{MeV}$ and ends at $1.25 \mathrm{GeV}$. The corresponding variation of velocity is from $\beta=0.5662$ to $\beta=0.9034$. Since the length of the rf cavity cells is $\mathrm{L}=\beta \lambda / 2$, it should in principle vary between 12.2 and $19.4 \mathrm{~cm}$, with $\lambda=42.83 \mathrm{~cm}$, the RF wavelength at $700 \mathrm{MHz}$, the chosen operating RF frequency of the SCL. To optimize the accelerating gradient it would be desirable to manufacture cavities with cells varying in length as the beam accelerates. This may not be economical, and we prefer to manufacture RF cavities all with the same cell length. This simplifies the design, and reduces the cost, at the expense of a modest reduction of the transit time factor. Here we assume that the SCL is divided in three sections each operating at three intermediate values of velocity. The super-conducting LE section, from 200 to $400 \mathrm{MeV}$, has the cavity cell length adjusted to the intermediate value $\beta=0.616$, the $\mathrm{ME}$ section, from 400 to $800 \mathrm{MeV}$, to $\beta=0.755$, and the $\mathrm{HE}$ section, from $800 \mathrm{MeV}$ to $1.25 \mathrm{GeV}$, is designed with the intermediate value $\beta=0.852$.

The layout of the Super-Conducting Linac is described in [4]. For more details see also the contribution to this Conference [3], where a SCL in pulsed mode is described. It is made of a sequence of identical periods each consisting of a Warm-Insertion for the location of focussing quadrupoles, steering magnets, vacuum pumps, and instrumentation, and of a Cryo-Module including a number of cavities all with the same number of individual cells. Each cavity is powered by a single RF coupler connected directly to one Klystron, the RF power source.

The parameters of the SCL are given in Tables 2 to 4. Table 3 shows the RF for the ME and HE sections to be $1.4 \mathrm{GHz}$, this gives a compact super-conducting structure with a total length of $160 \mathrm{~m}$ that may cost about $100 \mathrm{M} \$$ to be build. When the RF of $700 \mathrm{MHz}$ is chosen also for the last two sections, we found that the length and the expected cost have increased by about $20 \%$.

Table 2. SCL Parameters for 10-MW ACNS

\begin{tabular}{|l|r|}
\hline Increm. Linac Ave. Power & $8.4 \mathrm{MW}$ \\
\hline \hline Type of Particles & Protons $\left(\mathrm{H}^{+}\right)$ \\
\hline Kinetic Energy in entrance & $200 \mathrm{MeV}$ \\
\hline Kinetic Energy in exit & $1.25 \mathrm{GeV}$ \\
\hline$\beta$ & 0.9034 \\
\hline Momentum, GeV/c & 1.9769 \\
\hline Magnetic Rigidity, T-m & 6.594 \\
\hline Repetition Rate & $\mathrm{CW}$ \\
\hline Linac Duty Cycle, $\%$ & 100 \\
\hline Ion Source Current & $10 \mathrm{~mA}$ \\
\hline RFQ Transmission, $\%$ & 80 \\
\hline Chopping Ratio, $\%$ & 100 \\
\hline Linac Average Current, $\mathrm{mA}$ & 8.0 \\
\hline
\end{tabular}

\section{CONCLUSION}

When compared to a pulsed mode of operation, a CW SCL requires considerably much more cryogenic power and, despite a higher efficiency, more electrical AC power. In our case the AC power requirement needed just for the operation of the SCL exceeds $20 \mathrm{MW}$ that cannot be easily acquired on the BNL site. An energy recovery is thus desirable, as it can be obtained for example from the spallation target itself when this is operated in a hybrid configuration [5]. But on the other end, the performance of the accelerator in $\mathrm{CW}$ mode is expected to be more stable than that in pulsed mode when the peak performance values are even larger and pose a significant operational concern. Moreover, a non small feature is the lower intensity per bunch, as seen in Table 1, that 
removes some of the concern with beam halo formation and consequent latent, uncontrolled beam loss.

It should be reminded that the first proposal for a highpower proton SCL in the GeV energy range was the Accelerator-based Production of Tritium (APT) [6]. This also was to be operated in the $\mathrm{CW}$ mode, and the beam power required had an ambitious figure of hundreds of MW. Yet the design of the project was found to be entirely feasible, and removed several concerns for the application of superconductivity to a proton linear accelerator. We have all learned considerably from this earlier project of which the same design criteria still apply.

Table 3. General Parameters of the SCL

\begin{tabular}{|l|r|r|r|}
\hline Linac Section & \multicolumn{1}{c|}{ LE } & \multicolumn{1}{c|}{ ME } & \multicolumn{1}{c|}{ HE } \\
\hline \hline Ave. increm. Power, MW & 1.60 & 3.20 & 3.60 \\
\hline Average Beam Current, mA & 8.0 & 8.0 & 8.0 \\
\hline Initial Kinetic Energy, MeV & 200 & 400 & 800 \\
\hline Final Kinetic Energy, MeV & 400 & 800 & 1250 \\
\hline Frequency, MHz & 700 & 1400 & 1400 \\
\hline Protons / Bunch x 10 & 1.43 & 1.43 & 1.43 \\
\hline Temperature, ${ }^{\circ} \mathrm{K}$ & 2.1 & 2.1 & 2.1 \\
\hline \hline Cells / Cavity & 8 & 8 & 8 \\
\hline Cavities / Cryo-Module & 4 & 4 & 4 \\
\hline Cavity Separation, cm & 60.0 & 30.0 & 30.0 \\
\hline Cold-Warm Transition, cm & 70 & 30 & 30 \\
\hline Cavity Internal Diameter, cm & 12 & 6 & 6 \\
\hline Length of Warm Insertion, $\mathrm{m}$ & 1.30 & 1.30 & 1.30 \\
\hline \hline Acceler. Gradient, MeV/m & 8.21 & 22.3 & 22.7 \\
\hline Average Gradient, $M e V / m$ & $\mathbf{3 . 2 8}$ & $\mathbf{8 . 0 8}$ & $\mathbf{8 . 6 3}$ \\
\hline Cavities / Klystron & 1 & 1 & 1 \\
\hline RF Couplers / Cavity & 1 & 1 & 1 \\
\hline \hline Rf Phase Angle & $30^{\circ}$ & $30^{\circ}$ & $30^{\circ}$ \\
\hline Transverse Focussing & FODO & FODO & FODO \\
\hline Phase Advance / FODO cell & $90^{\circ}$ & $90^{\circ}$ & $90^{\circ}$ \\
\hline \hline Norm. rms Emitt., $\pi$ mm-mrad & $\mathbf{0 . 3}$ & $\mathbf{0 . 3}$ & $\mathbf{0 . 3}$ \\
\hline Rms Bunch Area, $\pi^{\circ}$ MeV & 0.5 & 0.5 & 0.5 \\
\hline
\end{tabular}

\section{REFERENCES}

[1] S. Shapiro et al., "Accelerator Based Continuous Neutron Source (ACNS)". BNL-Formal Report 71184. April 2003.
[2] SNS Design Report, 1.0-GeV SCL

[3] A.G. Ruggiero et al., contribution to this Conference, Portland, Oregon. May 2003.

[4] A. G. Ruggiero, "Design Considerations on a Proton Superconducting Linac". BNL-Internal Report 62312. August 1995.

[5] A.G. Ruggiero, "A Superconducting Linac as the Driver of the Energy Amplifier". Informal Report, BNL 63527, UC-414 AGS/AD/97-1. October 1996.

[6] A Feasibility Study of the APT Superconducting Linac. Edited by K.C.D. Chan. April 1996. Los Alamos National Laboratory, LA-UR-95-4045.

Table 4. Summary of the SCL Design

\begin{tabular}{|l|r|r|r|}
\hline Linac Section & \multicolumn{1}{c|}{ LE } & \multicolumn{1}{c|}{ ME } & \multicolumn{1}{c|}{ HE } \\
\hline \hline Velocity, $\beta$ : In & 0.5662 & 0.7131 & 0.8418 \\
Out & 0.7131 & 0.8418 & 0.9034 \\
\hline Cell Reference $\boldsymbol{\beta}_{\mathbf{0}}$ & $\mathbf{0 . 6 1 6}$ & $\mathbf{0 . 7 5 5}$ & $\mathbf{0 . 8 5 2}$ \\
\hline Cell Length, cm & 13.19 & 8.08 & 9.12 \\
\hline \hline Total No. of Periods & 7 & 8 & 8 \\
\hline Length of a period, m & 8.721 & 6.187 & 6.519 \\
\hline FODO-Cell ampl. func., $\beta_{\mathrm{Q}}, \mathrm{m}$ & 29.78 & 21.12 & 22.26 \\
\hline Total Length, m & 61.05 & 49.49 & 52.15 \\
\hline \hline Coupler rf Power, kW $(*)$ & 81 & 135 & 155 \\
\hline Energy Gain/Period, MeV & 30.00 & 50.00 & 57.50 \\
\hline Total No. of Klystrons & 28 & 32 & 32 \\
\hline Klystron Power, kW $(*)$ & 81 & 135 & 155 \\
\hline \hline$Z_{0} \mathrm{~T}_{0}^{2}$, ohm/m & 379.5 & 570.0 & 725.9 \\
\hline $\mathrm{Q}_{0}$ x 10 & 1.07 & 0.68 & 0.77 \\
\hline Transit Time Factor, $\mathrm{T}_{0}$ & 0.785 & 0.785 & 0.785 \\
\hline Ave. Axial Field, $\mathrm{E}_{\mathrm{a}}, \mathrm{MV} / \mathrm{m}$ & 10.4 & 28.4 & 29.0 \\
\hline Filling Time, ms & 0.778 & 0.802 & 0.714 \\
\hline \hline Ave. Dissipated Power, kW & 0.385 & 2.369 & 2.149 \\
\hline Ave. HOM-Power, W & 17.2 & 39.3 & 39.3 \\
\hline Ave. Cryogenic Power, kW & 0.506 & 2.486 & 2.272 \\
\hline Ave. Beam Power, MW & 1.60 & 3.20 & 3.60 \\
\hline Total Ave. rf Power, MW (*) & 2.16 & 4.32 & 4.86 \\
\hline Ave. AC Power for rf, MW $(*)$ & 3.69 & 7.39 & 8.31 \\
\hline Ave. AC Power for Cryo., MW & 0.359 & 1.763 & 1.612 \\
\hline Total Ave. AC Power, MW $(*)$ & 4.052 & 9.152 & 9.923 \\
\hline Efficiency, \% $(*)$ & 39.49 & 34.96 & 36.28 \\
\hline \hline
\end{tabular}

(*) Including $35 \%$ rf power contingency. 